\title{
Hybrid Model of MSMEs for Livestock Hype Product Facing Consumer Sudden Shift on Pandemics
}

\author{
A.E Kusumastuti ${ }^{1 *}$, J.A Putritamara ${ }^{1}$, S. Azizah ${ }^{1}$ \\ ${ }^{1}$ Department of Livestock Socio-economics, Faculty of Animal Science, Universitas Brawijaya , J1 \\ Veteran, Malang, Indonesia \\ Correspondence email: jaisyap@ub.ac.id
}

\begin{abstract}
Pandemic covid-19 breakout has a massive impact on the MSMEs sector. The majority of producers could not survive due to unpreparedness to face the economic shock due to declining purchasing power. So that, the research was designed to create a resilient strategy for business through a hybrid model with an analysis of planned behavior theory. The research focuses on livestock products that currently excites the community, intended for role models of agricultural food products as perishable food and susceptible to an unbalanced market. So that, the decline in purchasing power of the consumers is imbalanced with availability and vice versa. The selected products are mozzarella cheese and honey. The research used an interview survey method with producers and consumers. Data analysis used game theory to design a model that conforms to the condition of the business. Results of the research showed that hybrid model of MSMEs for mozzarella and honey (livestock products which are hype during a pandemic) has the optimization of strategy to bring more adaptive business into reality by improvising strategy of popularity for mozzarella product of brand $\mathrm{X}$ and improvisation from an advocacy perspective for a honey product of MSMEs brand X. MSMEs products have opportunity to acquire market and compete with big companies in each product because it has superiority that would be able to meet the consumer needs and conform to the purchasing power.
\end{abstract}

Keywords. advocacy, hybrid model, livestock, msmes, sudden shift.

\section{Introduction}

Micro, Small, and Medium Enterprises (MSMEs), or well-known as MSMEs, play a strategic role to contribute to the increasing Gross Domestic Product (GDP) for about $61 \%$ as presented in 20162019 MSMEs. It increases $4.2 \%$ per year. The growth indicates that MSMEs play a strategic role in increasing the national economy. 99\% of the businessmen in Indonesia are engaged in the MSMEs sector. The economic improvisation process from MSMEs is quite massive, starting from job expansion, stimulating the potential rural and urban resources to increase added value. The goal is to prosper the community on a bottom-up basis.

The uniqueness of the MSMEs sector can be seen when Indonesia had a crisis, the reduction of labor was increasing in the industrial sector. Still, MSMEs just become the main target to restore the community's economy because they can stimulate the growth of other sectors. Livestock is one of the sectors that can be collaborated with MSMEs sector to increase livestock competitiveness for food products. Collaboration of both sectors will stimulate the public sector to boost food sufficiency and product competitiveness from rural areas. The increased productivity of MSMEs is authentically 
potential as the pioneer of reliable local products with high value in both national and international markets.

Public sectors also stimulate the increased contribution of the MSMEs sector toward the national economy by mapping the regional potency with "one village, one product." Therefore, each potential area should have a superior product that contributes to the region's added value.

MSMEs of livestock products started to be developed because it has great potency in contributing to the availability of animal protein on a national scale. It also affects the continuation of the livestock business. All this time, the breeders face some difficulties at the downstream system due to the low bargaining position for livestock products. They highly depend on marketing institutions, but the existence of MSMEs has made the breeders stand-alone because MSMEs products have a vast market share.

In early 2020, pandemic covid-19 started to affect the performance of MSMEs, especially for business people who have minimum capital. A crisis resulting from health shock is different from a crisis caused by economic shock, as occurred in Indonesia in 1997. The unpreparedness of the producers in MSMEs, which affects the breeders, has reduced the business performance. The result of research by Soetjipto (2020) suggested that the turnover of MSMEs in the middle of May 2020 declined by 22.90 percent. As the impact of physical distancing, the logistics process had inhibited around 20.01 percent and 19.39 percent access to capital. MSMEs is the most susceptible sector against workforce absorption. Business uncertainty during a crisis has triggered the businessmen to adapt quickly to the economy's condition, which was different from the pre-pandemic breakout, so producers should establish an adaptive business strategy that will sustain. Each actor of MSMEs has other business characteristics, starting from the capitalization system to the products' distribution to the end-users, and has a different adversity quotient.

When we review the trend of consumer behavior at the beginning of the pandemic before the sudden shit occurred, the consumers had panic buying, and consumer behavior is slowly changing. Consumers increase the number of purchases of products that have a relationship with health values; even the purchased products tend to be immunomodulators. Most purchasing systems are used offline and online when the government makes a rule of social distancing. At last, the consumers decide to buy the products via an online system in case of health matters.

The majority of consumers in Indonesia are the millennial group who greatly influence the decision to purchase. Still, in general, a consumer is divided into two, namely native digital consumer and immigrant digital consumer. Not all consumers choose to get involved in purchasing activities via an online system because the immigrant digital consumer (the generation that adapts to the digital era comprises baby boomers and $\mathrm{X}$ generations) indeed chooses to purchase offline. In addition, the understanding level of technology affects the consumers in deciding to buy the product. Putritamara et al. (2020) Each generation has the attention and different assumptions regarding the valuation of dairy products. One of the efforts supporting this strategy is that the manager expands the agent through tours and travel to collaborate with consumers.

Consumer's decision to purchase via online and offline systems is characteristics of hybrid consumers with convergence between fulfillment the needs through cyber basis and traditional (Wind et al., 2002). Consumers have some reasons why do they carry out one of them or both. Producers admit that those behaviors are not difficult to be analyzed. In contrast, consumer behavior may change quickly in each different condition, so that it affects intention buying, which indirectly affects business strategy (Arnould et al., 2002).

Since 2018, consumers have come into the leisure economy, in which the producers engage the consumers through the pleasure side. The object that becomes trend indulgence is culinary business and tourism. When the culinary business became hype, but the economic condition changed due to health shock, the producers made a framework to make the business more adaptive. The whole MSMEs compete with each other not to get market but to survive. Referring to Hermawan Kartajaya's opinion, there is an opportunity in the middle of a crisis. The producers should know how to set a strategy and survive with more adaptive business capabilities to prepare for the subsequent 
uncertainty. Engemann and Wall (2009) changes in consumption during crisis periods are based on the customer's demographics.

Even livestock is categorized as a primary product, but Indonesia's amount of consumed livestock products is still low. Besides that, consumers of the livestock products have some specific categories, such as a) livestock products as the main product that must be fulfilled every day, b) the livestock products are only consumed in a specific moment, c) the livestock products are only consumed during religious holidays, and d) the livestock products are only consumed due to it become a trend in a certain period. Therefore, consumers of the livestock product are differentiated following types of product and demographic factors. Still, the pandemic has changed the economy so that the purchasing power of the public tends to change, and the consumer's reach of livestock products is decreasing. The objective of the research is to create a hybrid business strategy model. The hybrid concept was derived from the technology adoption level of the consumers. It is due to the consumer behavior as the targeting has some socio-cultural differences and then affects the decision to purchase, as well as the socio-cultural values, which could not be replaced by technology. However, based on business innovation, this model adapts to the technology adoption level of the consumers. A hybrid model is more adaptive to consumer behavior, financial condition, and needs. This model is easy to be simulated. The objective is to measure the implementation strategy so that the actors of MSMEs could increase their business performance because they can analyze the consumer expectation and measure their business position with the competitors. In challenging times, the assumption is that the producer can engage consumers starting from the hybrid consumer behavior based on the Theory of Planning Behavior that comprises influence factors, attitudes, consumer trust, intention to purchase, actual conduct, and other factors beyond expectation.

This research used game theory so that the selected strategy will be more implemented as an alternative by the actual condition of the consumers. This analysis also stimulates producers to make the competitors a reference and standard of comparison in establishing appropriate marketing strategies to face uncertainty because of pandemics. Research on a hybrid model with game theory on MSMEs of livestock products has not been carried out before. Therefore, the author initiated the creation of an applicative hybrid role model in the food sector. In contrast, the competitors of livestock products are commercial industries. Weaknesses of this research are lack of diversity and variation of products; therefore, it is less representative to conclude hybrid business strategies for all commodities. However, this research assists the following researchers in comprehending the characteristics of the consumers from MSMEs of livestock products. Therefore, it can be used as a base for the following business strategies, which are more innovative and adaptive in facing massive uncertainties.

\section{Research Method}

The research was conducted for two months, from April to June 2021, by survey method and case study on producers of mozzarella and honey. Dairy products, such as cheese and honey, were selected by the author by considering: 1) mozzarella tends to be an exciting product during pandemics when the public must stay at home, and one of their activity changes is shifting from outdoor to indoor, however, when they stay at home, most of them carry out housework, such as cooking and gardening. Therefore, a product, which increases during pandemics is cheese. Still, it is not as high as before pandemics when purchasing power was high; 2) the author determines the honey products under consideration that the public prefers to consume immunomodulator products during pandemics. Therefore, one of the livestock products which is assumed as a supplement of immunity booster is honey. Still, the weakness is, during pandemics, many producers sell unoriginal honey, so that it requires a strategy to compete with more innovative competitors and assure that the product is original; 3) competitors of both products are more adaptive commercial companies due to resources to innovate are high. The type of research is action research with game theory. The analysis result of game theory creates a strategy model that can implement in MSMEs of mozzarella and honey products. Respondents were determined by probability sampling with a simple random sampling method. Still, the purchasing system is divided into 2, namely consumers who buy online and offline data analysis using game theory. 
The basic idea of game theory is the strategic behavior of the player or decision-maker. It is assumed that each player has a set of plans or models that can choose. Meanwhile, the game is a specific action that must choose from a group of strategies. It is assumed that each player can make a decision independently and rationally. Therefore, this theory is not a way to get a solution to a problem that is not available, but it drives a strategic thought to solve a problem concerning decision (Aplak and Sogut, 2013).

This section should explain how you conducted your research. It should be written clearly and altogether containing a clear description of (i) population and sampling, (ii) data measuring and collecting, (iii) variable and data analysis. This research method should be sufficiently detailed so that it can reproduce the described procedure. For qualitative research, please adjust this method to your scientific writing habits while considering the repeatability of your research. It was not necessary to write analysis methods commonly (e.g., F-test formula, t-test), but just referred to your source. References of original methods/procedures must be stated and explain all procedure modifications (if any). Symbol description of the model was suggested to be written on narration.

\section{Results and Discussion}

A marketer introduced the hybrid model as an improvisation of a marketing strategy that can increase the purchasing power of the consumers adaptively. Different product segmentation made the producers comprehend the accessibility of the consumers to the products. In general, digital technology has provided new nuance for the consumers, particularly during a pandemic, which changes the purchasing system from face-to-face between the seller and the buyer turn to online. Such change is only valuable for consumers of the digital native, while the digital immigrant consumers must adapt to reach technology via social media, web, and e-commerce. To expand efficient strategy for all market segmentation, adaptive and strategic steps are required using the concept of theory planned behavior (TPB). Each consumer has a different intention in purchasing the product. This theory has developed and could assist the producers in analyzing and identifying the hybrid business model (conventional and modern marketing systems that are adjusted by consumer ability). Ajzen (2005) suggested that intention is affected by attitude toward behavior, subjective norm, and perceived behavior control.

The TPB concept adopted three indicators of measurement from Ajzen's concept. Those indicators comprise information, understanding of the consumer needs, popularity, and advocacy. Based on the measure of informative indicator, the product meets the expectation of the consumer's knowledge and provides information about the product. Based on the conventional perspective, both packaging and advertisement, producers should perform the products by the consumer's expectation, and input of the product must be understandable. Based on the marketing perspective online, producers should promote the products via social media and other marketplaces that conform to the originality of the products. Even when they collaborate with color features or photographic, they must keep the identity and totality (the whole parts) of the products to conform to the consumer's expectations when they purchase the products. The second behavior is producers understand the consumer needs. Producers should find out the needs of conventional market segmentation during pandemics. If the arrival intensity decreases, the strategy will come to the consumers, and increased practical values are the solutions.

Meanwhile, digital native segmentation is increasing the conversion of product sales by the funneling strategy. The third variable is popularity, both brand attribute, and company. The company can adapt to the consumer's lifestyle. Through conventional marketing, the producer chose to use a strategy of summing the intensity of consumer arrivals, while for online marketing, the strategy uses giveaways and bundling packages. A company should find out when the products become a trend and how to maintain some purchasing during hype among the community. The fourth variable is advocacy. The company designs a strategy by engaging consumers through conventional marketing by creating a visual and aesthetical package of products, which will motivate the consumer's intentions to purchase. For example, sold the honey product in bundling package with other supplements, cereal, and any 
products that support health during pandemics. A company should design the product aesthetically to make the audience landing page and converse the selling when using social media. The conventional and modern marketing strategies' selling conversion activities have simultaneously increased consumer's willingness to purchase and even end you at the level of recommendation to other potential consumers.

The research showed each 30 respondents from different company purchase records for mozzarella and honey products, 15 consumers who purchased directly at the booth, and 15 consumers who purchased via social media and e-commerce. Respondents of mozzarella and honey comprised of generation $\mathrm{X}$ and $\mathrm{Y}$. Conventional marketing method is the buyers transact directly with the producers. In contrast, in digital marketing, consumers purchase through social media and the marketplace.

Based on the research results, purchasing intensity increases and consumer awareness to consume nutritious products during health shock due to covid-19. Activities at home increase along with the increased need for food. The unique characteristics of the respondents toward intention to purchase cheese and honey are as follow:

1. $6.67 \%$ of consumers from generation $X$ are motivated by nutritional supplements (health factor).

2. $93.3 \%$ of consumers from generation $\mathrm{Y}$ are motivated due to the trend of cheese product.

Results of percentage indicate that mozzarella has an outstanding market share for generation Y. Generation $\mathrm{Y}$ has the power to affect other consumers in deciding to purchase cheese. The phenomenon of intention to buy cheese is different from honey product with some uniqueness as follow:

1. $43 \%$ of consumers from generation $\mathrm{X}$ are motivated to purchase honey products based on a health factor.

2. $57 \%$ of consumers from generation $\mathrm{Y}$ are motivated to purchase honey products due to the change of lifestyle during pandemics.

Results of percentage showed that during pandemics, the consumer intentions to purchase are not differentiated; all generations need honey products as an immunomodulator.

Sudden change in consumer behaviors is caused by shock factorial or so-called sudden shift. For example, cheese and honey are not the primary material for consumers in Indonesia, but the public tries to reach it even with low purchasing power to get the product, support needs, and wants. Therefore, the company should apply a strategy to compete with competitor products due to tight business competition during pandemics. Crisis during pandemics has made the majority of the companies initiate to expand their market, both commercial companies, and MSMEs. Some products have market differentiation; When the demand decreases, they blend and compete with the whole market segmentation as a frontal strategy to acquire consumers.

The research carried out game theory, and the results are as follows.

\section{Mozzarella Product}

During the pandemic, business performance in the MSMEs sector has decreased from the upstream process for procurement to downstream for market share. It is due to the purchasing power of the public falling. The unpreparedness of the MSMEs sector was also experienced by MSMEs of mozzarella brand $X$. Decrease in demand during early pandemics has affected the financial performance of the companies. Nevertheless, crisis condition insists all sectors survive with the fluctuating state of the market, and even supply and demand imbalances tend to occur. One of its efforts is to innovate to adapt to consumer's abilities. Unpreparedness resulting from health shock requires producers to design adaptive strategies due to dynamic market conditions immediately. Game theory analysis on this research assists the company in identifying consumer intention toward mozzarella. Results of the analysis are presented in the table below. 
Table 1. Output Game Theory MSMEs for Mozzarella Product

\begin{tabular}{lrrrrr}
\hline & Informative & By Need & \multicolumn{1}{l}{ Trend } & Advocacy & Row Mix \\
\hline Informative & 1,00 & 1,00 & 2,00 & 1,00 & \\
By Need & 5,00 & 2,00 & 2,00 & 9,00 & 1,00 \\
trend & $-3,00$ & $-4,00$ & $-3,00$ & $-4,00$ & \\
Advocacy & $-1,00$ & $-1,00$ & 9,00 & 4,00 & \\
\hline Coloumn Mix & \multicolumn{7}{c}{0,30} & & \\
& \multicolumn{7}{c}{0,70} & 0,30 & & \\
\hline Value of game & 2,00 & &
\end{tabular}

Game theory analysis on the mozzarella case used mixed strategies; it showed different values between maximin and minimax and resulted in a pay of 2.00. If MSMEs brand X competes with a mozzarella competitor from a commercial company of brand $\mathrm{Y}$, the minimum loss suffered by MSMEs $\mathrm{X}$ is 2.00 while the maximum profit of company $\mathrm{Y}$ is 2.00 . Each producer has a different strategy to understand the consumer intention to purchase the product. MSMEs brand $\mathrm{X}$ has a superior strategy by improvising the understanding of the needs of the niche market.

Customers have needs related to their problems and what products enable them to do [3,28]. Requirements depend on a situation, have different priorities, and can be identified without addressing them (Peppers and Rogers, 2011).

93.3\% market segmentation for brand $\mathrm{X}$ is generation $\mathrm{Y}$ that has significant opportunity to expand market share, even this strategy 0.30 more superior than the competitor. In contrast, the company of brand $\mathrm{Y}$ is a little more superior for trend strategy. Therefore, it has become a challenge for MSMEs brand $\mathrm{X}$ to reach the consumers through the trend. Improvisation of a hybrid model for MSMEs are as follow:

1. Conventionally, producers need to increase popularity, at least equal to that applied by competitors.

2. In a modern way, the producers should increase the selling traffic to diverse media, which consumers from generation Y mostly reach.

Brand popularity closely relates to purchasing intention, actual purchasing, and price-fixing (Lin et al., 2017). Those findings showed that it is essential to increase brand popularity as a focus in the marketing sector.

By reviewing the analysis result of game theory, each producer has strategy superiority that could weaken the competitor strategies. The superiority of understanding the consumer needs strategy toward honey MSMEs $\mathrm{X}$ is more substantial and able to beat the competitors. But, when the competitors have superior marketing strategies on popularity, brand X does not focus on that strategy. Therefore, it requires to measure effectiveness so that brand $\mathrm{X}$ can assure that marketing strategies are more effective. The following are the analysis results with a paired-T test.

Table 2. Paired Samples Statistics Test

Paired Samples Statistics

\begin{tabular}{rrrccc}
\hline & & Mean & $\mathrm{N}$ & Std. Deviation & Std. Error Mean \\
\hline Pair 1 & KMKM & 9.9667 & 30 & 3.85499 & 0.70382 \\
& $\mathrm{X}$ & 6.0333 & 30 & 3.85499 & 0.70382 \\
\hline
\end{tabular}

Source : (Primary data, 2021)

Results of the analysis showed a significant difference $(\mathrm{p}<0.05)$ between strategies applied by MSMEs brand $\mathrm{X}$, which are more outstanding and more effective, than the competitors in which brand $\mathrm{X}$ reached a practical value of 9.67 and the competitor was 6.033. This is the superiority of MSMEs to innovate, increasing the marketing strategy to be more resilient with the rapid changes in the economy and technology. Must take the effort to optimize the existing superiority and expand it by other adaptive strategies according to consumer needs. 


\section{Honey Product}

Honey becomes the superior product along with the change of consumer intention during the pandemic. A healthy lifestyle is a primary demand even purchasing power of specific segmentation is still low. Consumers start to categorize honey as a direct product. Problems of the honey producers during a pandemic are the agribusiness system and relate to quality and originality assurance of the product. Decrease in purchasing power of honey has made other competitors endeavor to get customers by creating an imitated product so that MSMEs X initiated a strategy that could increase the consumer's intention, which conforms to the consumer's ability so that TBP is considered as the representative to create an adaptive business strategy. The following are the analysis results of game theory by comparing MSMEs honey product and commercial companies as the leading competitor.

Table 3. Output Game Theory MSMEs Honey Product

\begin{tabular}{lccccc}
\hline & Informative & By Need & Trend & Advocacy & Row Mix \\
\hline Informative & 9,00 & 3,00 & 8,00 & 2,00 & \\
By Need & 10,00 & 4,00 & 4,00 & 3,00 & 0,92 \\
Trend & $-3,00$ & $-1,00$ & 3,00 & 3,00 & \\
Advocacy & 4,00 & $-3,00$ & 8,00 & 8,00 & 0,08 \\
\hline Coloumn Mix & & 0,42 & & 0,58 & \\
\hline Value of game & 3,42 & & & \\
\hline
\end{tabular}

Source : (Primary data, 2021)

Results of the analysis showed that strategies on the used game theory are mixed strategies because the maximin and minimax values are different, so the payoff value is 3.42. it means that if MSMEs honey product of brand $\mathrm{X}$ has plans that compete with the honey product of company $\mathrm{Y}$ (namely, one of the brands from the commercial honey product as the main competitor of brand $\mathrm{X}$ ), the minimum loss of MSMEs brand $\mathrm{X}$ is 3.42. On the other hand, the maximum profit of brand $\mathrm{Y}$ (commercial) is 3.42. Therefore, MSMEs honey product $X$ strategies have superior 0.50 more earnings than the competitor when optimizing the understanding strategy of consumer needs. It means that MSMEs can review the intention of the consumers to purchase, but during customer advocacy for brand $\mathrm{Y}$ (commercial competitor) is more superior to 0.50 than MSMEs. It indicates that the competitor brand has a superior strategy for changing consumer purchase intention and recommending it to potential buyers. This case tends to be normal due to competitors having strategies to maintain an expectation of consumer satisfaction through the customer journey. Therefore, the company could supervise the identification of the consumer intention up to the selling conversion level.

The customers' fundamental needs were seen as not changing frequently, but, for example, new types of technology trends were seen as creating new customer requirements. Market reports were used to some extent to anticipate future requirements. In addition, the company's customer needs database, which mainly included issues related to current products, was checked for future related needs. Finally, consider the internal customers' needs by inviting participation from the project organization's business lines, production, and customer operations. Internal discussions on needs were essential before entering the actual requirements into the tools (Majava et al., 2014).

The superiority of the competitors from advocacy strategy becomes a challenge for MSMEs honey product $X$ to improvise the advocacy strategy with a hybrid model as follows:

1. Conventionally, the producer should have the customer testimonials and attach them in an advertisement, both via flyers and pamphlets.

2. In a modern way, producers should engage the influencer and other customers who satisfy the honey product of brand $\mathrm{X}$.

Fransisco et al. (2021) suggested that more brands used influencers to market their products during this pandemic. Many brands have had to also change their way of promotion by advocating the use of masks and social distancing. This period has allowed for more interaction between the brands and the customers on social media platforms. Brands have had to connect with influencers who are real and 
loyal to their followers to promote products and information that is factual. It is also crucial that influencers research the brands that they are asked to upgrade. When deciding which brands to work with influencers, the users need to examine the brand's values and mission.

Reviewing the game theory results that each superiority (advantage) of the strategy designed by the producer can weaken the competitor's strategy. The superiority of the strategy that understanding the consumer needs toward honey MSMEs $X$ is stronger and able to beat the competitor, but with the advocacy strategy by competitors will be able to beat the advocacy strategy of MSMEs brand X. Therefore, further measurement is required, so that the company will be able to estimate whether the designed strategy is effective or ineffective. The following is the analysis result with the paired-T test.

\section{Table 4. Paired Samples Statistics Test}

Paired Samples Statistics

\begin{tabular}{lccrcc}
\hline & & Mean & N & Std. Deviation & Std. Error Mean \\
\hline Pair 1 & TRRL & 10.1333 & 30 & 5.68563 & 1.03805 \\
& $\mathrm{X}$ & 5.8667 & 30 & 5.68563 & 1.03805 \\
\hline
\end{tabular}

Source : (Primary data, 2021)

Results of the analysis showed significant difference $(p<0,05)$ between MSMEs strategies of brand $\mathrm{X}$ are doubled higher and more effective than the commercial company $\mathrm{Y}$, in which brand $\mathrm{X}$ is 10,13 and brand $\mathrm{Y}$ is 5.87. It is an excellent opportunity for MSMEs to innovate by increasing the marketing system to be more resilient and adaptive with the quick change in the economy and technology. Brand turned to trusted advocates, giving them creative control to add value to people's new realities (Enberg, 2020).

\section{$A$ hybrid model for both of company (brand $X$ and $Y$ in different products)}

Based on the result of cumulative analysis of strategy comparison with competitors, MSMEs marketing of cheese products has superiority on understanding consumer needs. Still, the weakness is in the trend strategy. On the other hand, while the cumulative analysis results for a honey product are that MSMEs honey of brand $\mathrm{X}$ has a superior strategy on understanding the consumers toward the needs, the strategy is weak on advocacy. Therefore, strategy optimization is required to increase the popularity of MSMEs products with a hybrid optimization model, as presented in Figure 1.

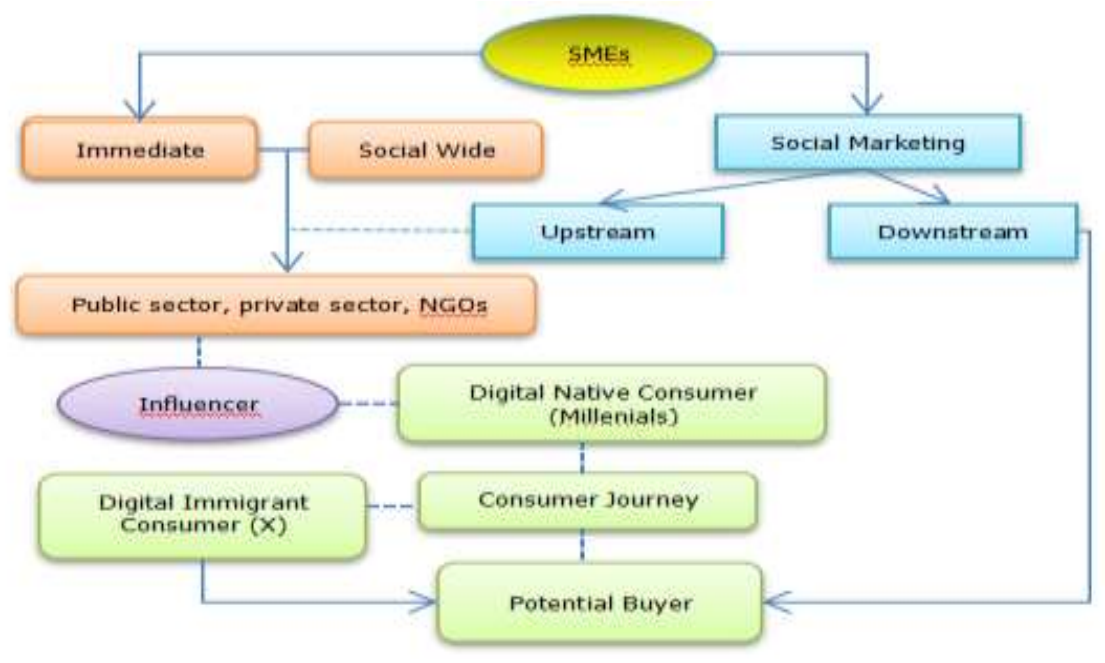

Figure 1. Model Hybrid of MSMEs Livestock Hype Product 
For MSMEs brand of mozzarella X, producers should apply promotion strategy with digital intervention. Not all niche markets are millennial but based on strength to affect other individuals, and power native can impact the potential buyer. Psychologically, consumers in the cyber era believe more in referral systems than promotion tactics by the company. So the improvisation of brand popularity should be confirmed through media that is visited by many millennial audiences. Brand developing through millennials will reduce the risk of high marketing costs. Therefore, MSMEs should create the fastest media, which can attract audiences visually. The visual promotion content is more attractive to the audience than verbal. Sharma et al. (2012) suggested that the ability of the human brain to process visual information is more significant.

If it refers to the basic concept of social marketing, the main focus is an intervention of change in consumer behavior (Gordon, 2013). But, by the change in technology, the focus becomes biased when the niche market is dominated by digital native, while the conventional marketing technique uses a downstream system. It means that if producers have the target, then no more voluntary behavior can provide recommendations to other potential consumers. This tactic is inefficient to reach digital natives because the community's characteristics that grow in the digital era are independent to get as much information as possible and a higher level of trust from experienced consumers. Therefore, an approach is required upstream. An analogy of upstream and downstream systems is if the river metaphor shows the urgency of upstream social marketing, which is illustrated by many drowning men in the downstream due to various factors in upstream so that it would not be enough to save the drowning men only. Therefore, some considerations are needed to overcome the problem that relates to the cause of drowning (Wallack et al. in Gordon, 2013).

Based on Social Cognitive Theory, human behavior is determined reciprocally by internal personal factors (for example, knowledge, and self-confidence) and environmental factors (such as facilities available in the local environment) (Bandura, 1986; Maibach and Cotton, 1995, in Hastings, 2007). This implies that individual behavior is determined by themselves and social context (Hastings et al., 2000).

\section{Conclusion and Recommendation}

The hybrid model of MSMEs for mozzarella cheese and honey (livestock products which are hype during a pandemic) has two strategies that must be optimized to bring more adaptive marketing strategy into reality, such as optimizing popularity strategy for mozzarella product of brand $\mathrm{X}$ and optimization strategy from advocacy aspect for MSMEs honey product of brand X. Both MSMEs have opportunities to get market and compete with commercial competitors of brand $\mathrm{Y}$ in each product because it has superiority that will meet the consumer needs. All stakeholders' recommendations to give massive support to MSMEs accelerate tactics towards adaptive strategies to get potential consumers and focus on them.

\section{Acknowledgments}

Special thanks to the Institute for Research and Community Service, Universitas Brawijaya, for the Grant Assistance Scheme on Novice Researcher in 2021.

\section{References}

[1] Ajzen, I. (2005). Attitudes, Personality, and Behavior. 2nd Edition. New York: Open University Press.

[2] Aplak, H. S., \& Sogut, M. Z. (2013). Game Theory Approach in Decisional Process of Energy Management for Industrial Sector. Energy Conversion and Management, 74, 70-80. http://dx.doi.org/10.1016/j.enconman.2013.03.027.

[3] Arnould, E. J., Price, L., \& Zinkhan, G. (2002). Consumer. end, McGrawHill, USA.

[4] Enberg, J. (2020). Influencer Marketing in the Age of COVID-19. Insider Intelligence. Retrieved from https://www.emarketer.com/content/influencer-marketing-in-the-age-of-covid19.

[5] Engmann, K., \& Wall, H. J. (2009). The Effects of Recessions Across Demographic Groups. 
Federal Reserve Bank of St. Louis.

[6] Fransisco, E., Fardoz, N., Bhatt, A., \& Bizel, G. (2021). Impact of the COVID-19 Pandemic on Instagram and Influencer Marketing. International. Journal of Marketing Studies, 13(2). https://doi.org/10.5539/ijms.v13n2p20.

[7] Gordon, R. (2013). Unlocking The Potential of Upstream Social Marketing. European Journal of Marketing, 47(9), 1525-1547. https://doi.org/10.1108/EJM-09-2011-0523.

[8] Hastings, G. (2007). Social Marketing: Why should the Devil have all the best tunes? (1st ed.). Burlington: Butterworth-Heinemann.

[9] Hastings, G., MacFadyen., \& Anderson, S. (2000). Whose Behavior Is It Anyway? The Broader Potential of Social Marketing. Social Marketing Quarterly, 6(2), 46-58. https://doi.org/10.1080/15245004.2000.9961102.

[10] Lin, H. C., Swarna, H., \& Bruning, P. F. (2017). Taking A Global View on Brand Post Popularity: Six Social Media Brand Post Practices For Global Markets. Business Horizons, 60(5), 621-633. https://doi.org/10.1016/j.bushor.2017.05.006.

[11] Majava, J., Nouttila, J., Haapsalo, H., \& Law, K. M. Y. (2014). Customer Needs in MarketDriven Product Development. Product Management and R\&D Standpoints. 5(1), 16-25. https://doi.org/10.4236/ti.2014.51003.

[12] Peppers, D., \& Rogers, M. (2011). Managing Customer Relationships: A Strategic Framework. (2nd Edition). John Wiley \& Sons, Inc., Hoboken, 2011.

[13] Putritamara, J. A., Azizah, S., Wisapti, U. N. N., Hariyono, M. B., \& Ridwan, S. (2020). Purple Ocean Strategy Implementation by Millennial Dairy Farmers in Malang, Indonesia. International Research Journal of Advanced Engineering and Science, 5(4), 166-169. http://irjaes.com/wp-content/uploads/2020/11/IRJAES-V5N4P178Y20.pdf.

[14] Sharma, A., Bhosle, A., \& Chaudhary, B. (2012). Consumer Perception and Attitude Towards The Visual Elements in Social Campaign Advertisement. IOSR Journal of Business and Management (IOSRJBM), 3(1), 6-17. Retrieved from www.iosrjournals.org.

[15] Soetjipto, H. N. (2020). Ketahanan MSMEs Jawa Timur Melintasi Pandemi Covid-19. Yogyakarta: K-Media.

[16] Wind, Y, Mahanjan, V., \& Gunther, R. E. (2002). Convergence Marketing: Strategies for Reaching The New Hybrid Consumer. Prentice Hall, USA. 